\title{
I am at my best when I slow down and that is what I will teach my trainees!
}

\author{
Yves d'Udekem, MD, PhD, FRACS
}

\footnotetext{
From the Department of Cardiac Surgery, Royal Children's Hospital; Murdoch Children's Research Institute; and Department of Pediatrics, University of Melbourne, Melbourne, Australia.

Dr Y.d'U. is a consultant for MSD and Actelion as well as a National Health and Medical Research Clinical Practitioner Fellow (grant No. 1082186). The Victorian Government's Operational Infrastructure Support Program supported this research project.

Disclosures: Author has nothing to disclose with regard to commercial support.

Received for publication March 1, 2017; accepted for publication March 2, 2017; available ahead of print April $12,2017$.

Address for reprints: Yves d'Udekem, MD, PhD, FRACS, Department of Cardiac Surgery, Royal Children's Hospital, Flemington Rd, Parkville, Melbourne, Victoria 3052, Australia (E-mail: yves.dudekem@rch.org.au).

J Thorac Cardiovasc Surg 2017;154:596-7

$0022-5223 / \$ 36.00$

Copyright $\subset 2017$ by The American Association for Thoracic Surgery

http://dx.doi.org/10.1016/j.jtcvs.2017.03.009
}

Among the most crucial determinants of patient outcomes is the quality of the surgery we provide. However, we do not have efficacious tools to assess it. The Boston team who elaborated the technical performance score $^{1}$ clearly intended to provide us with such a tool. Every scoring system goes through phases of trial and error and it is no surprise that the initial template would undergo successive modifications. ${ }^{2}$ Lodin and colleagues ${ }^{3}$ should therefore be congratulated for providing avenues to improve this score. They suggest that repetitive bypass runs as well as longer cardiopulmonary bypass and crossclamp times are predictive of higher rates of complications and higher resource use. But one should be aware of some potential bias in this study. The inclusion of patients with a double-outlet right ventricle and patients with right ventricle to pulmonary artery conduit implantation introduce variability to condition severity. The fact that these conditions predicted adverse outcomes confirm this suspicion. Some factors influencing the outcomes, such as valve sparing-operation and the nature of the patch, may have been surrogate markers of the differences among individual surgeons.

Estimating the quality of the repair remains essentially a subjective exercise, valid for ventricular septal defect, atrioventricular septal defect, and arterial switch, which were studied in the first version of the score. In tetralogy of Fallot there is still uncertainty regarding the best repair. The repair that will provide the best short-term outcomes may not best protect patients against late reoperation. Similarly, the valvesparing procedures improving early outcomes in the present study may well increase the rate of reoperation for outflow tract obstruction later. As mentioned, leaving a small residual gradient in the outflow tract likely reduces the risk of late complications and patients with no gradient in the outflow tract might be considered to have an inferior repair. ${ }^{4,5}$

Misreading some parts of this article may lead to poorer practice. Classifying reoperation as a complication is outcomes. trainees.

\section{References} 26:297-303.

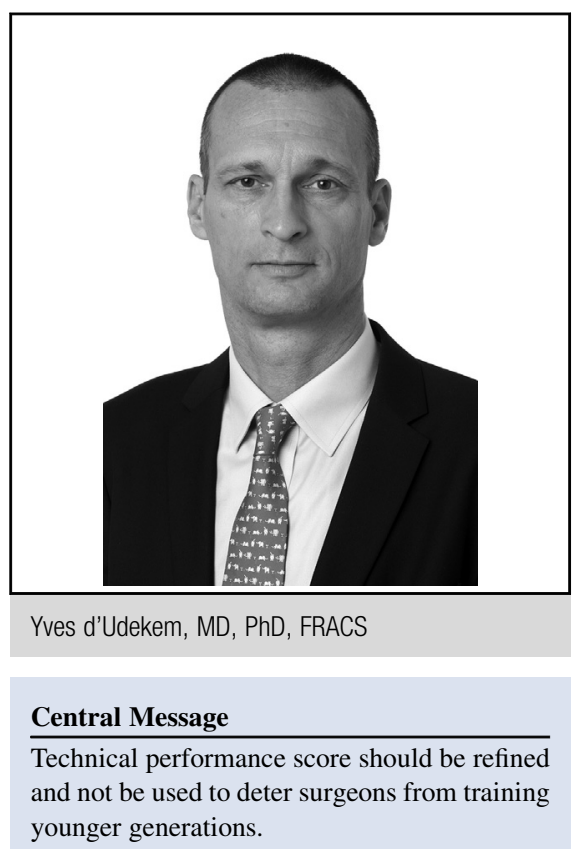

See Article page 585

appropriate. But it should not deter young surgeons from this practice in fear of a negative interpretation. Perfecting a repair by reoperation will often improve late patient

Unless proven otherwise, longer crossclamp times may be considered a marker of the severity of the disease rather than the inexperience of the surgeon. In our day and age, stating that faster operations are better is indiscriminate. A longer, more precise operation is better than a hastened, rushed, and imprecise one. In an age when hands-on training has decreased and there seems to be a lack of expert neonatal surgeons, we should be cautious to not discourage supervisors who allow younger staff to operate. I am at my best when I slow down and that is what I will teach my

1. Larrazabal LA, del Nido PJ, Jenkins KJ, Gavreau K, Lacro R, Pigula F, et al. Measurement of technical performance in congenital heart surgery: a pilot study. Ann Thorac Surg. 2007;83:179-84.

2. Nathan M, Marshall AC, Kerstein J, Liu H, Fynn-Thompson F, Baird CW, et al. Technical performance score as predictor for post-discharge reintervention in valve-sparing tetralogy of Fallot repair. Semin Thorac Cardiovasc Surg. 2014;

3. Lodin D, Mavrothalassitis O, Haberer K, Sunderji S, Quek R, Peyvandi S, et al. Revisiting the utility of technical performance scores following tetralogy of Fallot repair. J Thorac Cardiovasc Surg. 2017;154:585-96. 
4. van der Hulst AE, Hylkema MG, Vliegen HW, Delgado V, Hazekamp MG, Rijlaardsam ME, et al. Mild residual pulmonary stenosis in tetralogy of Fallot reduces risk of pulmonary valve replacement. Ann Thorac Surg. 2012;94:2077-82.
5. Frigiola A, Hughes M, Turner M, Taylor A, Marek J, Giardini A, et al. Physiological and phenotypic characteristics of late survivors of tetralogy of Fallot repair who are free from pulmonary valve replacement. Circulation. 2013;128:1861-8. 